\title{
Governing Social Practice
}

\section{Technology Versus Institutions}

Kallinkos, Jannis; Hasselbladh, Hans; Marton, Attila

Document Version

Final published version

Publication date:

2010

\section{License \\ CC BY-NC-ND}

Citation for published version (APA):

Kallinkos, J., Hasselbladh, H., \& Marton, A. (2010). Governing Social Practice: Technology Versus Institutions.

Paper presented at The EGOS Colloquium 2010 , Lisabon, Portugal.

Link to publication in CBS Research Portal

\section{General rights}

Copyright and moral rights for the publications made accessible in the public portal are retained by the authors and/or other copyright owners and it is a condition of accessing publications that users recognise and abide by the legal requirements associated with these rights.

\section{Take down policy}

If you believe that this document breaches copyright please contact us (research.lib@cbs.dk) providing details, and we will remove access to the work immediately and investigate your claim. 


\title{
Governing social practice: Technology versus institutions
}

\author{
Jannis Kallinikos, London School of Economics, J.Kallinikos@lse.ac.uk \\ Hans Hasselbladh Õrebro University (Sweden), hans.hasselbladh@gmail.com \\ Attila Marton, London School of Economics, A.Marton@1se.ac.uk
}

\begin{abstract}
This paper claims that technology and institutions both epitomize the construction of artificial orders through which a primary reality is shaped to something other than it is by logical operations that share essential affinities. Drawing on this, we work our way to showing how technology operates as governing regime and how tasks and operations that are carried out by the human enactment of expert rules and procedures can considerably be embodied onto technological sequences with which human experts have limited and severely structured interaction. These ideas are illustrated by reference to cultural memory organizations (e.g. libraries, archives, museums) and the ways the deepening infiltration of their operations by computing technologies redefines their goals and the skills, practices and arrangements through which these goals have traditionally been pursued.
\end{abstract}

\section{Introduction}

Institutions provide a potent lens for studying social relations. The variety of perspectives encountered within research on institutions notwithstanding, it would be possible to concur that institutional analysis revolves on the matrix of ideas, beliefs and practices out of which the fugitive nature of social interaction is moulded to stable social patterns that recur across societal fields. Whether as simple routines, arrangements (weddings, cocktail parties) or systems (e.g. health care, education), institutions are born at the confluence of ideas and practices, beliefs and rules, meanings and the ways these get embedded in social life. Thus understood, institutions stand opposite to the causal relations found in nature (Searle 1995) and operating independently of human agents, even though the personal associations they occasion may vary widely. A sunset may be beautiful or distressing but differs essentially from a wedding ceremony, a cocktail party or a board meeting. Institutional analysis is exactly that conceptual project by means of which the processes that establish and sustain institutional reality are bracketed for further investigation.

While convincing, the understanding of institutions in these terms (Meyer and Scott 1983; Roy 1977) causes a sort of an aporia as to how institutions relate to the material world and all other circumstances that may seem to fall outside what prima facie counts as institutions. A specific yet vital question therein concerns the place of technology in institutional analysis and the role technological arrangements may assume in both the reproduction of institutions and institutional change (Pinch 2008; Runde et 
al. 2009). Technology may seem at a remove from institutional relations and, in a sense, it is. For, technological patterns, whether physical/material or of an information-processing type, are objectified relations that have been embodied to machines and thus lifted out of the immediate encounters of humans. In some straightforward and irrevocable ways, the patterns and relations technology embodies stand outside the contested zones in which human interests, skills and goals are daily traded. ${ }^{1}$

But this, we contend, is a deceptive appearance of a much more complex and subtle system of relations. A historical awareness of the matrix of economic and social relations out of which modern technology emerged suggests that the latter has played a crucial role in the construction of modern organizations and the governance of economic life. Computing technology in particular, claims Beniger, in his The Control Revolution: Economic Origins of Information Society, is a potent system of methods and devices for steering and controlling the unprecedented productive forces unleashed by industrial capitalism. Through an elaborate analysis of the administrative methods and techniques for controlling production and distribution on large national markets, Beniger demonstrates the essential involvement of computing technologies in the management of modern organizations and the alternative or complimentary steering regime they have provided to the system of rules and formal positions by which bureaucratic governance is commonly associated (Beniger 1986). ${ }^{2}$

Recent developments coinciding with the diffusion of the internet and the massive involvement of technologies of computing and communication in nearly every walk of life vividly demonstrate the relevance and timely character of our observations (Benkler 2006; Castells 2001; Lessig 2006). And yet, the institutional implications of technologies have so far failed to penetrate institutional analysis in any substantial way. The basic reason for such a state of affairs certainly is the widespread assumption that institutions as contrived yet legitimate social orders stand diametrically opposite not simply to the givens of nature but also to "any purely instrumental or provisional practical arrangement that is recognized as such" (Douglas 1986: 46). Against this backdrop, it comes as no surprise that the logics through which technology versus institutions are involved in the making and governance of social practice have seldom been given attention. We lack an adequate understanding of the mechanisms or processes by means of which technology and institutions come to intersect one another (Marton 2009; Pinch 2008). Or, as we claim in this paper, we do not yet understand

\footnotetext{
${ }^{1}$ We distinguish here between the politics of designing and developing technological artefacts versus the enclosed functionalities they embody once developed and stabilized (see, e.g. Bijker et al. 1987).

${ }^{2}$ See also Yates (1989) and Kallinikos (2004).
} 
well the terms on the basis of which things and processes carried by institutional means (e.g. routines, role systems, norms) can be offloaded to technologies and perhaps vice versa. It is obvious that routine and standard operating procedures are easier to translate to technological patterns. Less well understood is the logical structure of the operations that permit that conversion and the limits to which it is subject. To address this issue, it is necessary to unpack the nature of the operations embedded in technological systems versus the stable arrangements and practices with which institutions are associated and explore whatever affinities they may share. For, any conversion from one system of relations to another presupposes an affinity on the basis of which that conversion takes place.

In this paper, we seek to pursue some of these issues building on our earlier work on the subject (Hasselbladh and Kallinikos 2000; Kallinikos and Hasselbladh 2009). After this brief introduction, we turn to the task of laying bare the logic by which institutions are involved in the making and governance of social relations. We draw heavily on Searle's pioneering reconstruction of what he calls institutional facts at the same time as we seek to relate critically to his conceptual edifice (Searle 1995, 2008, 2010). This is followed by our attempt to place technology within the matrix of relations that reproduces and governs social practices and discover the link tying governance by technology to governance by institutional means. As we explain at some length over the next two sections, technology and institutions epitomize the construction of artificial orders of projective (forward looking) nature through which a primary reality is shaped to something other than it is by logical operations that share essential affinities (e.g. declarative statements versus design). On the basis of this, we work our way to showing how technology operates as governing regime, and how tasks and operations that are carried out by the human enactment of expert rules and procedures can considerably be embodied onto technological sequences with which human experts have limited and severely structured interaction. These ideas are illustrated by reference to cultural memory organizations (e.g. libraries, archives, museums) and the ways the deepening infiltration of their operations by computing technologies redefines their goals and the skills, practices and arrangements through which these goals have traditionally been pursued.

\section{The distinctive nature of institutions}

While often associated with ritualized performances and the reproduction of the social order, institutions originate in imaginative ways of conceiving reality (Castoriadis 1987). In some fundamental and affirmative way, institutions are fabrications, ways of construing life versions, social relations and modes of conduct that are substanti- 
ated through a protracted process of objectification and meaning solidification (Berger and Luckmann 1966; Douglas 1986; Meyer and Jepperson 2000).

Essential then to institutions is the making of reality as other than it is. In his remarkable and provocative book The Construction of Social Reality (CSR) that plays with Berger and Luckmann's classic title, ${ }^{3}$ Searle spends a significant amount of effort to drive the point that institutions emerge exactly when an attribute, quality or function (Y) is attached to some thing (an X) that this thing (X) cannot carry on the basis of its own intrinsic constitution (Searle 1995). He gives a variety of examples ranging from money through presidents to weddings and cocktail parties. The five-dollar bill in his pocket, Searle claims, is money (an institution) by human agreement. Neither the sheet of paper nor the imprinting on that paper would be enough to make the fivedollar bill money. The materiality of cellulose and the imprinting on the paper both lack the intrinsic qualities of the things that can be bought (the value) by money, as kind barter and to a certain degree gold do. The status of money (Y) has therefore to be conferred upon an object $(\mathrm{X})$ by means of collective agreement (meaning negotiation), itself a complex accomplishment that may require the existence of other institutions or institutional relations (e.g. the US central bank).

The history of money and its recent migration to electronic tokens suggests that money status can be conferred by deploying a variety of material or technical means. The connection, therefore, between status/function and material support is established by convention or rule, and for that reason it is not intrinsic. Or to turn the argument around, whatever entails intrinsic relations and causalities is not an institution. The general formula of institutional facts, Searle claims, is the following: $\mathrm{X}$ (the dollar bill) counts as $\mathrm{Y}$ (money) in $\mathrm{C}$, where $\mathrm{C}$ is the context (US, the world or a historic period in the example of money). In other words, institutions coincide with the creation and imposition of status function (Y), in a context $\mathrm{C}$, on an object $(\mathrm{X})$ that lacks that status function on its own and is assigned this function by collective agreement. ${ }^{4}$ Property, hierarchical role systems, legal status (i.e. corporations), the labour contract are other ubiquitous institutions constructed though the imposition of status functions upon a primary reality whose entities (land, a human group, resources, work) lack that status functions.

\footnotetext{
${ }^{3}$ Indeed, Searle claims that social reality cannot be but constructed. The "social" in the phrase "social construction of reality" could accordingly be seen as redundant.

${ }^{4}$ Collective intentionality obviously relates to legitimacy, a central concern of institutional theory. We will only deal with this issue very briefly in the end of this section. To do otherwise would have meant a considerable digression from the main goal of this section which is no other than disclosing the elementary operations by which institutions are brought to being.
} 
Reduced to its barebones, Searle's claims portray institutions as coinciding with the invention and imposition of a status function on something that intrinsically lacks that status function. This is a simple and seductive claim at the same time. It would be worth to point out in passing that the establishment of institutions as a complex process of invention/imposition of status function upon a primary complex of relations and materials, whether at local or field level, has often been glossed over in institutional research (see e.g. Hasselbladh and Kallinikos 2000; Hirsch and Lounsbury 1997; Meyer and Jepperson 2000) that has predominantly been concerned with the diffusion of institutions. There are obvious reasons for this state of affairs. The power of institutions to govern social life is directly related to them being standard components in the social and economic fabric. Justified as it may be, such a concern has nonetheless tended to overlook the nature of institution building and obscure the entanglement of institutions with the primary reality out of which they emerge.

Following the CSR, Searle has sought to elaborate and refine the logical structure of this process by means of which institutions are established and maintained (Searle $2008,2010)$. In these later works, institutional facts are more explicitly tied to particular types of speech acts and language, described as a master-institution, is assigned a critical role in the process of institution building. ${ }^{5}$ The potential in all human languages to transcend the functions of a mere signalling system is attributed paramount importance. Human languages are unique in that they represent in the wider sense of mediating real, intended or imagined states. In other words, language affords a variety of modes of relating to the world, including descriptions (statements and beliefs) and performative utterances (orders, promises, declarations) and Searle sets out to explain how that particular affordance of human language is mobilized in the creation of what he refers to as deontic reasons, reasons to act that are independent of our desires or inclinations (2008: 451, 2010: 9), with which institutions are closely associated. Human interaction entails reasons for acting that are independent of the parties interacting at a particular time and place. While communication and interaction remain commonly localized to the interacting parties, the symbolic boundaries of interaction stretch far beyond situated encounters into a sphere impregnated of symbolic meanings that is not simply carried by language but whose very existence is dependent on language. Translated into common social science parlance, this assumes situated interaction as cast in a framework of cultural rules and norms mediated by language,

\footnotetext{
${ }^{5}$ A very similar view on language is central to the entire work of Castoriadis (cf. 1987).
} 
stretching beyond interaction itself. Searle's contribution is that he addresses the question of how deontic reasons come into being straightforwardly.

Basically, deontologies are created by a subset of performative utterances, that is, Declarations. ${ }^{6}$ If successful, a Declaration always creates a status function (X counts as $\mathrm{Y}$ in...). Declarations are singled out from other types of performative utterances in that they have the elusive quality of relating to the world by mixing descriptions (propositional content) with performatives and thus achieving what Searle describes as a double direction of fit between statement and world. Whereas descriptions usually map the world and can be assessed in terms of truth or falseness, in Declarations descriptions are ways of verbally construing reality as different, as when $\mathrm{X}$ (the world) counts as Y (the world as changed) in C.: "We thus achieve the world-to-word direction of fit, but we achieve that direction of fit by way of representing the world as having been changed, that is, by way of word-to-world direction of fit." (Searle 2008: 451, 2010: ch. 4). The clue here, we suggest, is the "world as having been changed". What Searle tries to capture is the intertwining of stating and creating in the use of language, at least in principle simultaneously, by making a statement that follows certain logic. For instance, the opening of the parliamentary session is in one sense 'reported'. Language is used to represent what is taking place, i.e. the session is opened. But at the same time, and that is what lends particular powers to Declarations, the same statement actually commands the world by way of representing the world as assuming a new status due to the statement itself; the parliament is by, through and due to this statement changed in its state of being; it is from now on in session. The phrase that reports the opening of the parliamentary session also, at the same time, literally creates a change of status of the reality it reports about.

Herein, could one maintain, reside the powers of human creativity in construing a set of relations out of another, being that the institution of the sacred, money, nations or ideologies, weddings or cocktail parties. Searle is very explicit in his claims about the fundamental importance of Declarations in establishing institutional reality: "with the important exception of language itself, all of institutional reality is both created in its initial existence and maintained in its continued existence by way of representations that have the same logical structures as Declarations" (Searle 2008: 451, italics in original).

\footnotetext{
${ }^{6}$ According to Searle, there are five types of illocutionary utterances: Assertives (intentional representations of thing "as they are"), Directives (orders and commands), Commisives (promises and vows), Expressives (declarations of subjective feelings and experiences) and Declarations (the literal creation of institutional facts).
} 
In fact, the role assigned to Declarations represents a crucial qualification of Searle's arguments as they have initially been developed in the CSR, where he claimed that institutional facts are created by iterated applications of constitutive rules (principles and procedures of which the game of chess provides an instructive example). He concludes that constitutive rules ( $\mathrm{X}$ counts as $\mathrm{Y}$ in $\mathrm{C}$ ) simply represent a special case of Status Function Declarations and their particular form of logic (ibid: 453-454). There exist, however, three different types of Status Function Declarations. These are the following:

a) Standing Declarations or Constitutive Declarations - declaring into the indefinite future that anything that satisfies the $\mathrm{X}$ condition counts as having the $\mathrm{Y}$ status. Such Declarations establish the conditions for producing institutional tokens out of an institutional type (a winner in a certain type of political elections, a legitimate father of a child, a violator of the tax code etc). Needless to say, Standing Declarations are dependent on an existing network of institutional relations that have already acquired Status Functions (Searle 1995: 116). Status Functions of this sort are the building blocks of a modern society's expert systems, administrative structures and procedures and formal knowledge.

b) Ad hoc Declarations - the non-formal acceptance of that X counts as $Y$ here and now. No literal Declaration is made but acts (including speech acts) performed over time create deontic powers even though these may lack explicit formulation; for instance a general agreement that some people in a group should have their say before others express their views. This type of Declarations is obviously the type of institutional constructions most cherished by the tradition of social science inspired by Berger and Luckmann (1966). Such institutional constructions are accomplishments of human interaction at the micro-level with little or no formal reasoning or involvement of formal institutional structures beyond this particular context.

c) Declarations by using free standing status functions - the imposition of a status function without any pre-existing object or person on which the status function is imposed. ( ) counts as $\mathrm{Y}$ in... This is an ex nihilo creation - the thing that is to be assigned a function status (Y) does not yet exist. In order to create the particular type of double direction fit, typical of all Declarations, the operation must be supported by a range of means for materializing the speech act. The creation of a company (the example Searle uses for free standing status functions) is not valid unless the literal Declaration is represented by means of certain rules and resources 
(the Declaring act is written down, testified and saved according to specifications etc).

In its basic form, Searle's model of Declarations of status is very simple but encompassing. In principle, anything can be understood in the terms offered by the model, from the creation and reproduction of a small sports union to the global world order. According to Searle, complexity in institutional settings arise primarily (perhaps only) due to aggregation. Chains of institutional facts are derived from previously established facts, and interlock and shape networks or systems of institutional facts, such as a monetary or political system. Searle seems to consider the constituting act important as far as it creates a function, that $\mathrm{X}$ is accepted as $\mathrm{Y}$, which is a binary or instant outcome (even though he mentions in passing that institutions might develop gradually over time). The model can be used to analyze extensive networks of institutional facts (such as the monetary system) but each and every component of such a system differs only in terms of which of the three basic types of Declaration they are dependent on. As a philosopher, and a philosopher of language in particular, Searle is less interested in the particularities and frictions surrounding each and every type of institutional system in the modern society. Elections or money are interesting as they provide an opportunity to say something decisive about the ontological status of what we refer to as society. We, as social scientists, do however see a number of intriguing paths to pursue if Searle's ideas are interrogated in more detail.

For Searle, it suffices to conclude that Declarations are expressions of collective intentionality. He is less interested in analyzing different conditions of accepting Declarations. The collective intentionality Searle considers as an emergent property of language must, unconditionally, result in acceptance if the act of expressing a declaration is to bring an institution into existence. No acceptance, no institution and Searle is keenly aware of the limits of coercive powers in enhancing acceptance. Even though institutions seldom are enforced at point-blank, it is however important to understand 'the context of creation' - is a Declaration accepted in a group of equals, in group of adults and children, in communication between the public at large and experts, in formal communication between managers and employees or even in the 'corrective work' between prison wards and inmates? Regardless if asymmetries as such are a main concern for research, it is necessary to acknowledge that different categories of actors in the contexts of modern society display considerable differences in terms of access to resources (not least discursive), status and formal rights. 
Aware of these concerns, Searle has in Making the Social World introduced the concept of recognition. In contrast to acceptance, recognition does not necessarily imply consent, endorsement or preference (Searle 2010). One may recognize money as an essential element of modern life and an institutionalized medium of transactions, even though one may hate it or consider it as harmful to human culture. Institutions need collective recognition to exist, even though a stronger form of collective intentionality, which Searle subsumes under the concept of cooperation, is often necessary to sustain institutions. Engaging in transactions of buying and selling is an example of cooperation which occurs against the background of the recognition of money as an essential medium of exchange. Here is how he puts the issue: "the existence of an institution does not require cooperation but simply collective acceptance or recognition. Particular acts within the institution such as buying and selling or getting married or participating in an election require cooperation", Searle (2010: 58).

Drawing on these observations, we could claim that a considerable part of neoinstitutional research has so far predominantly focused on one particular type of institutional construction; that is, how local Ad hoc Declarations stabilize and transform to Standing or Constitutive Declarations whether at the field, national or international level. Most of these investigations usually follow how a local set of relations become institutionalized, that is, transformed from Ad hoc to Standing Declarations. Or, the other way around, how a Standing Declaration, empirically identified with some kind of structural pattern or a set of explicit rules, can be tracked back to its origins in a locally negotiated order. Common to both these approaches is the assumption that the crucial question to be answered is how acceptance and/or recognition are accomplished (legitimacy in the terms used in the neo-institutional school). What values were invoked, what types of actors were involved and what types of knowledge were put to use? In the following, we will argue that institutional change, understood as paramount change of goals, norms, rules and identities can come about without passing through the volatile and unpredictable processes of creating acceptance and recognition, if the changes are mediated through technology.

\section{Technology versus institutions}

Some of our earlier remarks provide reasons as to why Searle's portrait of institutions must be enriched by the study of the factors that condition the embeddedness of Declarations in social life and their transformation to institutions. At the same time, the social minimalism of his theory enables him to bypass the complex social arrangements associated with institutions and lay bare the logical structure out of which institutions emerge. Undeniably, the seductive powers of his model owe much to his abil- 
ity to abstract the essential operations of institution making from the messy complexity with which they are entangled.

The double fit of Declarations (word-world and world-word) and the deontic powers Declarations embody provide, we maintain, the model of reality creation on which technology draws as well. Strange as this analogy may seem at first glance, it becomes comprehensible once technology is conceived as that artificial (in the sense of contrived) order, whereby a function or set of functions (Y) is conferred upon materials, processes or logical procedures in the case of software $(\mathrm{X})$ that lack that function. What is accomplished through Declarations in the case of institutional facts is brought to being through Design in the case of technology. For that reason, the sciences of design, as Simon referred to technology and engineering sometime ago, by necessity break away from the descriptive ideal of science (word-world fit) and become prescriptive and projective transforming the world to fit human goals (world-word fit) (Simon 1969). In this respect, technological artefacts are brought to being by a logical structure that bears strong similarities to the one that establishes institutional facts. To the status functions of Declarations and their deontic powers correspond the technological functions and the prescriptive and projective order they lay out. If this is true then the similarity of logical structure of Declarations with Design provides the terms by means of which a commensurable social space is established whereby governance by institutional means can be exchanged for governance by technology. The logical structure of Design and Declarations delineates the passageway through which technology treads upon institutional relations.

An essential difference, however, separates technological functions from institutional status functions as described by Searle. It belongs to the distinctive nature of institutions to be brought to being by status functions and the acceptance or recognition these obtain across a wide range of situations (Searle 2010). The 'status' of status functions is key to institutions, for the world is presented and made different by the distinctive ontology of status functions that is no other than the collective ascription of meaning, enabled by language, upon entities or relations that lack that meaning. Acceptance or recognition of the status function among the members of a community is crucial for that function to fulfil its deontic role (e.g. this is a board meeting and not a cocktail party). In simpler words, institutions depend on the interpretive (in a primary sense) ability of human agents to enact the institutional mandate the status function embodies. The constitutive and regulative implications of institutions are never mechanical even though they may often, as the literature demonstrates (cf. Zucker 
1988; Barley and Tolbert 1997), acquire the character of taken-for-grantedness and be invoked without immediate reflection.

Searle himself distinguishes between status functions and agentic functions as when a function is crafted upon a material to make it a tool, utensil or instrument (Searle 1995, 2010). Though it is not entirely clear, Searle seems to think that agentic functions may not necessarily imply collective imposition of function, as for instance when a craftsman makes an object in relative isolation (Searle 2010: 59-60). In terms of social ontology, agentic functions are mind-dependent but not language-dependent, and can be developed by non-human animals as well. However, in the majority of cases, technical objects are cultural tokens of types widely diffused in a culture such as a chair, a table or, for that matter, a procedure for authenticating passwords. In this respect, agentic functions and the activities of designing and developing an artefact are collective in an analogous way of status functions resting on recognition. As a rule, the more complex an artefact is the more ramified it gets into a web of social and instrumental relations. This is important to stress as technologies in the current world are increasingly embedded in networks of interdependent operations. The key difference then between status functions and advanced technological functions is the far more elaborate objectification of the latter and its embodiment onto operations that are considerably self-going or automated. In thus embodying functions in artefacts, technological design transposes deontic considerations (rules, rights, obligations) into pragmatic or instrumental relations.

It is crucial to understand the subtle shift implied by the transformation of a status function to a technological function and the implications it has for governing human behaviour. The use (as opposed to design and development) of technological functions does not presuppose acceptance or recognition, at least not the ways the enactment of status functions does. As soon as the politics of design and development of technologies is stabilized in a set of functional attributes embodied onto the technological object or system, the hermeneutics of enacting the status functions is not any longer an indispensable part of the collective effort. An important shift is thus accomplished through both the neutralization of the different perspectives, resources and interests which the acceptance and recognition of Declarations may engender and the considerable simplification of the process of locally enacting the institutional mandate (Hasselbladh and Kallinikos 2000). Technology adoption, of course, engenders its own problems but these are predominantly framed as issues of cost, functional compatibility and learning. The skills necessary to operate technological objects transpose the issue of the enactment of the institutional mandate of status functions from a deon- 
tic/interpretive enterprise to one where skilfulness and efficiency dominate. In other words, technological design collapses the $\mathrm{X}$ counts as $\mathrm{Y}$ in $\mathrm{C}$ by superimposing the $\mathrm{Y}$ on the $\mathrm{X}$ and standardizing its use. The uncertainties of the intersubjective negotiation of reality and the invocation of different perspectives that are inevitably tied to the "count as" are replaced by considerations of a different type. It is for these reasons and by means of these differences that technology and institutions can emerge as alternative regimes of governing social practice.

Function certainly is a subset of meaning but the superimposition of the $\mathrm{X}$ and $\mathrm{Y}$ upon the same medium transforms the processes through which technologies and technological systems are invoked and operated. It is a key attribute of technology to shift coordination away from social agents and entrust them onto the operations that constitute its regulative space (Kallinikos 2006, 2009). In this respect, technology entails a strategy for mediating social relations that shifts away from role making and the interiorization of norms, scripts and action schemes that are inexorably involved in the regulation of social relations by institutional means. Such processes are often complex, messy and contingent on a variety of conditions against which technological operations are usually fenced off. In this regard, the transition from the institutional means of governing social relations to technology coincides with the considerable social and functional simplification of the environment in which technologies operate (Luhmann 1993). Technologies are often complex accomplishments but the environment (social, physical or natural) in which they operate is intentionally streamlined and simplified.

Placed against the background of these observations, the hermeneutics of technology about which much ink has been spilled over the last two decades (see e.g. Bijker et al. 1987; Orlikowski 2000; Runde et al. 2009; Suchman 2007) acquires a different meaning. That hermeneutics does not concern the processes through which the functions of an artefact or system come to pass; for these have been taken away from negotiation and become black-boxed. The human agent is often an intermediate or last step in a long series of operations that are carried out by objectified and automated means/ends sequences, secluded from immediate intervention. What is negotiated is the integration of a system or artefact into the wider ecology of relations that define a practice (Barley 1986; Lanzara 2009; Pinch 2008) not the operations such a system or artefact embodies. One can, for instance, decide whether and how to drive a car or recollect its significance in one's life but the mechanics of driving are, and happily so, nonnegotiable on the fly. The same applies to software and all computational artefacts that prima facie seem more malleable, as we show in the next section. A technological 
artefact or system is thus simplified so as to exclude the irruption of external contingencies into the unfolding of its technological operations which thus remain protected from external interference.

Drawing on similar observations, we have in our earlier work juxtaposed technological regulation to two other major regimes of shaping and controlling social relations in organizations, namely those of social structure and culture (Kallinikos and Hasselbladh 2009) that have been the traditional objects of institutional analysis (see e.g. Scott 2001). What we offer as contribution in this paper is the logical structure that connects them together, the common currency, as it were, that justifies considering them as alternative regimes for governing social relations that put different emphasis on what and how is governed. Social structure and culture are the offspring of a logic that recounts the structure of Declarations as depicted above and the means through which they get embedded in social life. Technology, on the other hand, is the outcome of Design and the far-reaching objectification of technological functions as depicted in table 1, below. There are obviously nested territories between the three and social areas that remain ambiguous and under no exclusive regulative regime. The introduction of elaborate technologies to carry out tasks that were previously conducted by relying on the other regimes transform yet does not eliminate the elaborate social framework and the cultural schemes on which they relied. But it does end up parsing reality differently and reapportioning what can be accomplished by technological versus institutional means (Kallinikos and Hasselbladh 2009).

Table 1: Regulative Regimes in Social Practice

\begin{tabular}{|c|c|c|c|}
\hline & TECHNOLOGY & SOCIAL STRUCTURE & CULTURE \\
\hline Strategies & $\begin{array}{l}\text { Functional Simplifica- } \\
\text { tion, Closure }\end{array}$ & $\begin{array}{l}\text { Stratification, } \\
\text { Functional Differentia- } \\
\text { tion }\end{array}$ & World Framing \\
\hline Modalities & Automation & $\begin{array}{l}\text { Routines, } \\
\text { Rules, } \\
\text { Standard } \quad \text { Operating } \\
\text { Procedures }\end{array}$ & $\begin{array}{l}\text { Norms, } \\
\text { Perceptions, } \\
\text { Expectations }\end{array}$ \\
\hline $\begin{array}{l}\text { Agency } \\
\text { Forms }\end{array}$ & Skill Profiles & Formal Role Systems & $\begin{array}{l}\text { Models of Action, } \\
\text { Modes of Conduct }\end{array}$ \\
\hline \multicolumn{3}{|c|}{ Objectification } & Subjectificatior \\
\hline
\end{tabular}


As shown in table 1, the differences are captured along three axes entailing, 1) the strategies by which the complexity of the world is reduced and selective action patterns are constructed, 2) the means through these goals are accomplished and 3) the agency forms they implicate. The means (modalities) deployed to accomplish the mediation/regulation of the social relations suggests that the three regimes differ in the emphasis they put on objectification versus subjectification (norm interiorization) as the primary mode of shaping agency forms (Miller and O'Leary 1986; Rose and Miller 1992). Indeed, introducing technologies to organizations and other domains of social practice (e.g. professions) has been closely associated with the quest of transferring the execution of tasks from humans (subjects) to objects (machines) and whatever real of imaginary gains this has perceived to offer.

\section{Technology and memory institutions}

In this section we turn to exemplifying some of the claims we have advanced so far with reference to the developments that are currently taking place in cultural memory institutions in general and libraries in particular. What we present below is part of a larger empirical project on the forms through which information technologies currently reconfigure the infrastructural bases of institutions. We have in what follows compiled a picture of cultural heritage institutions and libraries based primarily on secondary and widely available sources. While our exposure in the field is a prerequisite for using these secondary sources meaningfully and skilfully, what we offer below should not be seen as theory test but rather as an effort to assemble a context of relevance in which the theoretical ideas presented above can be fleshed out and illustrated.

Memory organizations have emerged out of the practices of collecting, categorizing and preserving knowledge, art and social evidence. The institutionalization of these practices into the organizational forms of libraries, museums and archives is closely related to the development and differentiation of communication media. The institution of the library, in particular, has acquired its distinctive institutional identity thanks to its focus on the collection, categorization, access provision and preservation of mass produced communication media - most notably books (Dahl 1958; Lee 2000; Bennett 2001; Baker 2006). The library takes care of one copy of many rather than of unique or rare items which can be found in archives and museums. In other words, the books selected by libraries receive the new status-function of cultural heritage artefacts through a process of canonization that is associated with librarianship as professional practice. This is a key deontic reason (among others) for understanding libraries; that is the elevation of books from being mass produced consumer goods, embedded into a network of relationships entailing authors, readers, publishers, printing in- 
dustry, educational institutions and so forth, to a status of a cultural heritage artefact as part of social memory (Assmann 2008). In what follows, we focus on this societal role of a dedicated trustee of cultural heritage and leave education and research related deontic reasons aside.

In Searle's (1995) terminology we can state "this binded stack of pages (X) counts as a book (Y)". 7 However, it takes a library for a book (X) to count as a cultural heritage artefact (Y). In an equivalent fashion, we can formulate constitutive rules for unique or rare documents and archives as well as for unique or rare artefacts and museums. To clarify, we define a book as a communication medium mass produced for an anonymous mass audience in opposition to manuscripts or inkunabula (early print books) which would usually be preserved in a book museum (Dahl 1958; Weinberger 2007). However, with the rise of online interaction and the digital media it brings forth, memory organizations find themselves, in addition to their traditional environment, in a field whose essential elements are shaped by the contemporary technologies of computing and communication. Libraries, archives and museums face new players (e.g. Google or Amazon), new ways of organizing knowledge and information (e.g. search engine algorithms and social tagging), new types of user behaviour (e.g. social network communities or interactive user interfaces) and new communication media (e.g. email, tweets, hypertext or blogs) which defy their institutionalized practices and roles as gatekeepers to information and guardians of knowledge (Primary Research Group 2008).

Traditionally, librarian practices evolve around the selection (collection management), organization (cataloguing) and preservation of mostly printed mass media. Taken together, these practices result in the canonization of librarian items into cultural heritage artefacts, on the one hand, as well as the accessibility and usability of the librarian repository by non-professional users, on the other hand (Ranganathan 1931; Thompson 1982). In comparison, the digitization of the items themselves is a relatively recent development that complements the digitization of the documentation and description of the items, referred to as descriptive meta-data in today's lingo that preceded it. The catalogue was the first to be digitized and brought into a database which allowed for enhanced discovery functionalities and, with the rise of the internet, access to the catalogue from beyond the walls of the library. The databased computa-

\footnotetext{
${ }^{7}$ See, for instance, the definition of a book on the online Oxford Dictionary: "a written or printed work consisting of pages glued or sewn together along one side and bound in covers". Source: http: / / www.askoxford.com/concise oed / book? view=uk, accessed on $9^{\text {th }}$ May 2010.
} 
tional rendition of the catalogue still remained within the traditional librarian rationale; in fact some advanced database functionalities were first formulated by librarians (Weinberger 2007). By contrast, the digitization of the items themselves heralded a fundamental transition in terms of how cultural heritage artefacts are being constituted. Let us explain.

The digitized version of the book is in fact not a 'version' but rather a heap of data organized into computer files and assembled into an emulation of a book (an e-book) by software applications. Consequently, a digital library does not collect already institutionally stabilized items but reconstructs books through a variety of means and procedures which information technologies afford. A digital library makes books by emulating a momentary rendition of its content - it gives structure to data. For instance, scanning a book with Optical Character Recognition technology (OCR $)^{8}$ delivers raw computational text. For the raw text to become a book again, the structure of the book (paragraphs, lay outing, etc.) needs to be encoded into, so called, structural meta-data which is nothing more than a set of instructions for an application to process the data and to present it in the right format in order for a user to become a reader. One could of course just read the raw text but that is a very different experience than reading a book that conveys content in a structured way based on standards and conventions that took four centuries to develop (Bearman and Trant 2005).

In other words, the book as the primary object of library practices is currently no more than a series of automated (objectified and standardized) software-based operations by which a heap of data and data structures are assembled into an emulation of a recognizable cultural unit. The elementary unit of the digital library thus shifts from books to data stored in computer files (Svenonius 2000). The librarian cultural heritage artefact exists only insofar as it is being processed by technological means; it only exists as a logical entity. A set of structural meta-data is a key element of this logical entity as it specifies how the artefact is to be processed. Differently put, structural meta-data describes an artefact of which it is a part of. Consequently, the digital cultural heritage artefact becomes autological, it describes itself (Marton 2010). Descriptive meta-data makes the items findable, structural meta-data makes the items themselves accessible and usable as emulations. In a sense, structural meta-data is the equivalent to the binding of the book.

\footnotetext{
${ }^{8}$ OCR scanning recognizes printed characters and translates them into computational text. While this works relatively well with standard fonts, it obviously reaches a limit with hand-written manuscripts and incunabula which are usually scanned as page wise images.
} 
The described imposition of technological functionality on the assemblage of an ebook coincides with the assignment of the status of a cultural heritage artefact, since the books digitized for a library are already cultural heritage artefacts; that is, a library digitizes its own collection already consisting of cultural heritage artefacts. ${ }^{9}$ In other words, what we described as the emulation of an e-book is, in fact, the emulation of a cultural heritage artefact $(\mathrm{Y})$ that binds data $(\mathrm{X})$ within the context of a library information system. However, the autological constitution of digitized cultural heritage artefacts does not complement traditional librarian practices (as it is the case with databased catalogues) but rather entails a transformation of the librarian artefact's status function into a technological function. Let us elaborate by taking preservation as an example.

Being a key competence of memory institutions, preservation entails not only the maintenance of the material integrity of the collected items but is also the basic requirement for providing findability and accessibility not only today or the next year but also the next decade or even century. As we have already discussed above, metadata (like every binary based code) requires the appropriate soft- and hardware in order to be processed correctly. Since technological standards are continuing to become obsolete in ever shorter periods of time, data, supposedly preserved by a library, may turn out to be inaccessible rather sooner than later. A famous example is the digitization of the historical Domesday Book - an exhaustive survey of medieval England commissioned by William the Conqueror in 1086 . Only 15 years after the project, the file formats were already unreadable by computer systems of that time. It took the combined efforts of experts from Leeds University and University of Michigan to make the digitized version accessible again (BBC 2002). This is indeed an enormous problem for contemporary society as a whole that has not been solved yet and it may become more difficult to solve as technological changes becomes both more rapid and diversified.

Preservation is increasingly becoming an information technological issue rather than a skilful, rule-based practice. Since the binary code of the digitized book itself is not accessible to human intervention, it is not recognizable as such either. Instead, it needs to be mediated by specialized software applications. In a way, the institutional fact of "this stack of pages counts as a book" is replaced by the tightly coupled computational interaction between code and software. It takes a specific application to

\footnotetext{
${ }^{9}$ In contrast, this is not the case with online born-digital communication media which offer a different kind of challenge in terms of selection and preservation discussed elsewhere (Kallinikos et al. 2010).
} 
process specific instructions in a specific way turning the cultural heritage artefact 'book' into a black-boxed digitized cultural heritage artefact 'e-book'. As the example of the Domesday Book project shows, just a change in one of the tightly coupled components that constitute the technological artefact can dissolve it into mere noise, requiring nearly archaeological efforts to reconstruct it again. As a consequence, the digitized cultural heritage artefact does not lose its status function because of a lack of collective agreement but rather because the technology does not work. This is true not only for the data stored but also the structural and descriptive meta-data since all these aspects are encoded as bits and bytes.

In more abstract terms, if the functionally simplified connection between data, metadata and software fails, the digitized cultural heritage artefact may as well have never existed. The meta-data functions as an equivalent to the "count as" of the statusfunction. Metaphorically speaking, it is the glue that holds the pages together. Based on the remaking of the librarian elementary unit through information technological means, we can observe a gradual imposition of a new order that challenges governance by rules, formal roles and norms (see Table 2, below). For one, the distinction between libraries, archives and museums is becoming increasingly permeable. While museums have specialized rules and standard operating procedures which differ profoundly from those applied by libraries as well as archives, digitized cultural heritage artefacts form a foundation upon which technological processes promote a functional unification of memory institutions. Cast in digital format, paintings, books, documents, newspapers and so forth turn into data, subject to the same information technological regime of functional simplification and containment. In this sense, it may be more appropriate to refer to these recent developments as digital memory organizations rather than digital libraries, digital archives and digital museums respectively. In fact, they all do the same; the persistent maintenance of the technological coupling of data, meta-data and software which allows for services such as the discovery and accessibility of digitized cultural heritage artefacts. In a sense, this is true for any information system. With memory institutions, however, the coupling needs to stand the test of time.

As a consequence, information technology related skills and practices gain an increasingly central role within memory institutions. For instance, in addition to descriptive meta-data, documentation on file type structures, software specifications or even hardware blueprints may be recorded to provide for technical provenance, which turns every digital memory organization into a museum or historical archive of information technology. Persistent resource identifier services are being implemented to allow for 
persistent findability of documents available online. These services offer an alternative to the URL system, which identifies 'locations' rather than documents for a user of the Web to navigate to. Skills such as data-migration or emulation of obsolete information systems gain importance in order to guarantee the readability and integrity of the data. Especially the last example emerges as a purely technological necessity to keep an information system up-to-date with new standards. However, these regular updates contradict the key responsibility of memory institutions to guarantee the authenticity of the collected artefacts. Updatability is indeed a form of forgetting (Kallinikos 2006). Since the digital cultural artefact consists of the coupling of data, meta-data and software, the question arises whether a migrated database produces the same artefacts as before the migration. After all, data migration changes the data and, as a consequence, the digital cultural heritage artefact, emulated out of data, loses its authenticity. When it comes to emulating obsolete IT standards, we face a similar problem, since the emulator may change the cultural heritage artefact when mimicking the coupling between data, meta-data and applications as it was originally designed.

Going back to the notion of preservation, we have to ask what does a digital memory organization actually preserve? Digitized cultural artefacts are abstract operations based on information technological processes. In order for these to become digitized cultural heritage artefacts, the technological function needs to be preserved for future generations. This is the very basic foundation upon which the traditional services, we are familiar with, can be offered by digital means, such as granting remote access to a historical document, visiting a virtual exhibition or reading a book online. If the technological coupling of data, meta-data and software malfunctions, we may lose whole cultural collections or, possibly even worse, the collection may end up being distorted and modified.

\section{The entanglement of technology with institutions}

The transformation of libraries and the key functions of preserving and mediating knowledge described above indicate that technological developments have important institutional correlates. This is the immediate conclusion to be drawn from the technological remaking of the key institutional mandate of collecting, cataloguing, preserving and mediating knowledge that is associated with libraries qua institutions presented above. Often incrementally, technology penetrates particular regions of institutions and through its gradual embeddedness across a large spectrum of tasks and operations it ends up remaking the primary object and the social practices by which institutional orders are sustained and reproduced. 
But does the institutional mandate of libraries and memory institutions in general change because of these developments in what may be envisaged as the lower order of institutions, that is, the very infrastructure upon which the daily operations of institutions rely? Do these practical and instrumental arrangements that Mary Douglas firmly, and perhaps rightly, places outside the sphere of institutions manage in the end to encroach and remake institutional relations? Do the institutional goals of preserving knowledge, art and social evidence and making them available across time and space undergo significant transformation as the outcome of technological developments? After all, libraries, archives and museums do continue to deliver their services or do they?

Addressing these questions is of course contingent on how technology is understood. We have been at pains to show throughout this article how technology operates as an elaborate system of social coordination parallel to rules, routines and roles, beliefs and understandings that are usually tied to regulation/constitution of social action by institutional means. Our empirical reconstruction, of how contemporary technologies of computing and communication get involved in cultural memory institutions, provides a reasonable testimony to our theoretical claims. As technology gains momentum and becomes pervasive, it inexorably comes to redefine not simply particular tasks and operations but also the identity of institutions and the role they play within the wider social and institutional context.

Given the increasing digitization of artefacts and the blurring of the traditional original/copy distinction, it will increasingly be difficult to maintain the distinctive profile of practices, skills and routines that have been associated with the organizational differentiation of cultural memory institutions into libraries, archives and museums. A technologically mediated, functional unification of longstanding organizational distinctions seems to be driven by the digitization of the respective cultural heritage artefacts and the meta-data enriched, online services the digitization affords. However, these developments do not imply the definite decline of the collection, cataloguing and preservation of traditional material such as printed books, paintings or paper documents. Material cultural heritage artefacts will continue to be managed by libraries, archives and museums. The outcome of the conflating practices of traditional and digital media is hard to predict. Still, just as the digitization of a book does not deliver a mere digital version of that book but rather a new cultural artefact, so too the digitization of librarian practices does not result in a digital library but something qualitatively different. Although digitization projects are referred to as digital libraries (e.g. the World Digital Library), digital archives (e.g. the Digital Archive of the Scottish 
National Library) or digital museums (e.g. the Virtual Museum of the Pacific), they are functionally indistinguishable from one another. These online services are libraries, archives and museums by name only. The objects of the social units that result or will result from these projects and the practices by which these objects would be collected, maintained and mediated would be of a substantially different nature than that of traditional memory institutions.

The functional unification is clearly reflected in the practice of preservation - a key expertise of memory institutions. Preserving a book, for instance, by rebinding or, maybe even replacing it, is very different from preserving or restoring a valuable artwork. However, preserving an e-book and a high-resolution digital image of a piece of art is critically contingent on the procedure of maintaining the tight coupling between data, meta-data and soft-/hardware, essential for assembling the emulation of book or image that in the end are the services delivered online. The same basically applies to accessibility. While accessing a book in a library is very different from an artwork in a museum (the first can be used or even borrowed, the latter can be visited in an exhibition and accessed by only selected experts), digital cultural heritage artefacts are found and accessed based on, again, the tight coupling of data, meta-data and soft-/hardware, irrespective of whether it is an e-book or a piece of artwork or a document for that matter.

The comprehensive nature of the changes brought about by information technology introduces, we contend, a new regulative regime into cultural memory institutions that takes the social form of a technology-driven assemblage of tasks and operations by means of which digital cultural memory is produced and maintained. Such a regime (e.g. database cataloguing) complements traditional practices but it also undermines them (e.g. digital cultural heritage artefacts). It is indeed reasonable to conjecture that the embeddedness of that regime may lead to the renegotiation of fundamental concepts closely associated with the institutional mandate of cultural memory organizations, such as authenticity or provenance.

Drawing on these observations we have sought to plot in table 2 below the distinction of the regulative regimes we advanced earlier in this article (see table 1) onto cultural memory institutions and the developments we have described in this article.

Table 2: Regulative Regimes in Memory Institutions

$$
\text { TECHNOLOGY SOCIAL STRUCTURE CULTURE }
$$




\begin{tabular}{|c|c|c|c|}
\hline Strategies & $\begin{array}{l}\text { Functional Unification of } \\
\text { Libraries, Archives and } \\
\text { Museums into Memory Or- } \\
\text { ganizations }\end{array}$ & $\begin{array}{l}\text { Differentiation into Librar- } \\
\text { ies, Archives and Museums }\end{array}$ & $\begin{array}{l}\text { Trustee of Cultural Heri- } \\
\text { tage and Social Memory }\end{array}$ \\
\hline Modalities & $\begin{array}{l}\text { Tight Coupling of Data, } \\
\text { Meta-Data and Soft- } \\
\text { /Hardware }\end{array}$ & $\begin{array}{l}\text { - Canonization } \\
\text { (Collection, Catalogu- } \\
\text { ing/Categorization, Preserva- } \\
\text { tion); } \\
\text { - Access Provision } \\
\text { - Provenance of Documents }\end{array}$ & $\begin{array}{l}\text { - Representative Collec- } \\
\text { tion of a Domain or So- } \\
\text { cial Unit; } \\
\text { - Authenticity of Items; } \\
\text { - Trusted Source }\end{array}$ \\
\hline $\begin{array}{l}\text { Agency } \\
\text { Forms }\end{array}$ & $\begin{array}{l}\text { IT-Competencies } \\
\text { (Database Maintenance, Pro- } \\
\text { gramming, Data Migration, } \\
\text { Emulation, Digitization) }\end{array}$ & $\begin{array}{l}\text { - Professionalized Expertise } \\
\text { in Collection Management } \\
\text { (Selection, Cataloguing), } \\
\text { Helpdesk, Preservation }\end{array}$ & $\begin{array}{l}\text { Neutral Guidance to } \\
\text { Knowledge and Infor- } \\
\text { mation }\end{array}$ \\
\hline \multicolumn{3}{|c|}{ Objectification } & Subjectification \\
\hline
\end{tabular}

Institutions we claimed, following Searle, are created by language and the deontic power of Declarations. However, the abstract and contrived nature of the mandate carried by successive Declarations needs to be embedded in social practices through which it is transformed to tangible outcomes, that is daily operations and services. Technology usually targets routine and standardized operations that support the normative/deontic framework declarations establish. In this regard, the techniques, skills, routines and standard operating procedures that define social practice become the Trojan horse through which technology enters the institutional order. This does not necessarily mean that technology enters institutions through a bottom-up, local process of diffusion. The negotiation of particular tasks and operations and their technological embodiment does not occur in situ, even though this may occasionally happen. Rather, the technological embodiment and transformation of practices that were once predominantly performed by humans are the outcome of Design as the generic phenomenon of conceiving and objectifying functions rather than as situated accomplishment. Therein lies the power of technology to regulate social practice and tread upon the world of institutions.

\section{References}

Assmann, A. (2008) 'Canon and Archive', In: A. Erll and A. Nünning (eds) Cultural Memory Studies: An International and Interdisciplinary Handbook. Berlin, New York: Walter de Gruyter, pp. 97-107.

Baker, D. (2006) 'Digital Library Futures: a UK HE and FE Perspective', Interlending \& Document Supply, 34/1: 4-8.

Barley, S. (1986) 'Technology as an Occasion for Structuring: Evidence from Observation of CT Scanners and the Social Order of Radiology Departments', Administrative Science Quarterly, 31: 78-108.

Barley, S. and Tolbert, P. (1997) 'Institutionalization and Structuration: Studying the Links between Action and Institution', Organization Studies, 18/1: 93-117. 
BBC (2002) 'Digital Domesday book unlocked', http://news.bbc.co.uk/1/hi/technology/2534391.stm, last access: $13^{\text {th }}$ March 2010.

Bearman, D. and J. Trant (2005) 'Converting Scanned Images of the Print History of the World to Knowledge: A Reference Model and Research Strategy', Russian Digital Libraries Journal, 8/5: http://www.elbib.ru/index.phtml?page=elbib/eng/journal/2005/part5/BT

Beniger, J. (1986) The Control Revolution. Cambridge, MA: The MIT Press.

Benkler, Y. (2006) The Wealth of Networks. New Haven: The Yale University Press, also freely available in www.benkler.org.

Bennett, S. (2001) 'The Golden Age of Libraries', The Journal of Academic Librarianship, 27/4: 256-59.

Berger, P. and Luckmann, T. (1966) The Social Construction of Reality. London: Penguin.

Bijker, W. E., Hughes, T. P. and Pinch, T. (editors), 1987, The Social Construction of Technological Systems. Cambridge, MA: The MIT Press.

Castoriadis, C. (1987) The Imaginary Institution of Society. Cambridge: Polity Press.

Castells, M. (2001) The Internet Galaxy. Oxford: Oxford University Press.

Dahl, S. (1958) History of the Book. New York: Scarecrow Press.

Douglas, M. (1986) How Institutions Think. Syracuse: Syracuse University Press.

Hasselbladh, H. and Kallinikos, J. (2000) 'The Process of Rationalization: A Critique and Reappraisal of Neo-institutionalism in Organization Studies', Organization Studies, 21/4: 697-620.

Hirsch, P. H. and Lounsbury, M. (1997) 'Ending the Family Quarrel: Toward a Reconciliation of "Old" and "New" Institutionalisms', American Behavioural Scientist, 40/4: 406418.

Kallinikos, J. (2004) 'The Social Foundations of the Bureaucratic Order', Organization, 11/4: 13-36.

Kallinikos, J. (2006) The Consequences of Information: Institutional Implications of Technological Change. Cheltenham: Elgar.

Kallinikos, J., Aaltonen, A. and Marton, A. (2010) 'A Theory of Digital Objects', First Monday, 15/6 (forthcoming).

Kallinikos, J. and Hasselbladh, H. (2009) 'Work, Control and Computation: Rethinking the Legacy of Neoinstitutionalism', in Research in the Sociology of Organizations, 27: 257-282, special issue on Institutions and Ideology, R. E. Meyer, K. Sahlin, M. J. Ventresca and P. Walgenbach (eds).

Lanzara, G. F. (2009) 'Reshaping Practice: Material Mediation, Medium Specificity and Practical Knowledge in Judicial Work', Organization Studies, 30/12: 1369-1390.

Lee, H.-L. (2000) 'What is a Collection?', Journal of the American Society for Information Science, 51/12: 1106-13.

Lessig, L. (1999/2006) Code and Other Laws of Cyberspace. New York: Basic Books and www.lessig.org (creative commons license).

Manovich, L. (2001) The Language of New Media. Cambridge, Mass: The MIT Press.

Marton, A. (2009) 'Self-Referential Technology and the Growth of Information. From Techniques to Technology to the Technology of Technology', Soziale Systeme, 15/1: 13759. 
Marton, A. (2010) 'The Autological Constitution of Digital Cultural Artefacts. An Analysis of the Implications of ICT on Memory Organizations', LAEMOS, Buenos Aires: http://www.egosnet.org/jart/prj3/egosnet/data/uploads/LAEMOS\%202010/ST 4 LAE MOS-2010 Marton.pdf.

Meyer, J. W and Jepperson, R. L. (2000) 'The "Actors” of Modern Society: The Cultural Construction of Social Agency', Sociological Theory, 18: 100-120.

Meyer, J. W. and Scott, R. W. (eds) (1983) Organizational Environments: Ritual and Rationality. Beverly Hills, Calif.: Sage.

Miller, P. and O'Leary, T. (1987) 'Accounting and the Construction of the Governable Person', Accounting, Organizations and Society, 12/3: 235-265.

Orlikowski, W. J. (2007) 'Sociomaterial Practices: Exploring Technology at Work', Organization Studies, 28/9: 1435-1448.

Pinch, T. (2008) 'Technology and Institutions: Living in a Material World', Theory \& Society, 37: 461-483.

Primary Research Group (2008) Libraries \& the Mega-Internet Sites: A Survey of how Libraries use and relate to Google, Yahoo, Wikipedia, eBay, Amazon, Facebook, YouTube \& other Mega Internet Sites. New York: Primary Research Group Inc.

Ranganathan, S. R. (1931) The Five Laws of Library Science. London: Edward Goldston.

Rose, N. and Miller, P. (1992) 'Political Power beyond the State: Problematics of Government', British Journal of Sociology, 43/2: 173-205.

Roy, W. G. (1997) Socializing Capital: The Rise of the Large Industrial Corporation. Princeton: Princeton University Press.

Runde, J., Jones, M., Munir, K. and Nikolychuk, L. (2009) 'On technological Objects and the Adoption of Technological Product Innovations: Rules, Routines and the Transition from Analogue Photography to Digital Imaging', Cambridge Journal of Economics, 33/1: 1-24.

Searle, J. (1995) The Construction of Social Reality. London: Penguin.

Searle, J. R. (2008) 'Language and Social Ontology', Theory \& Society, 37: 443-459.

Searle, J. R. (2010) Making the Social World: The Structure of Human Civilization. Oxford: Oxford University Press.

Simon, H. A. (1969) The Sciences of the Artificial. Cambridge, MA: The MIT Press.

Suchman, L. (2007) Human-Machine Configurations, Second enlarged edition of Plans and Situated Actions. Cambridge: Cambridge University Press.

Svenonius, E. (2000) The Intellectual Foundation of Information Organization. Cambridge: MIT Press.

Thompson, J. (1982) The End of Libraries. London: C. Bingley.

Weinberger, D. (2007) Everything is Miscellaneous : The Power of the New Digital Disorder. New York: Times Books.

Yates, J. (1989) Control Through Communication: The Rising of System in American Management. Baltimore: John Hopkins University Press.

Zucker, L. (ed.) (1988) Institutional Patterns and Organizations, Cambridge, Mass: Ballinger. 